\title{
Erratum to: Cushioning the Fall: Scandals, Economic Conditions, and Executive Approval
}

\author{
Ryan E. Carlin • Gregory J. Love • \\ Cecilia Martínez-Gallardo
}

Published online: 1 April 2014

(C) Springer Science+Business Media New York 2014

\section{Erratum to: Polit Behav \\ DOI 10.1007/s11109-014-9267-3}

In the original publication of this article, Table 2 was incorrectly printed. The correct version of Table 2 is shown below.

The online version of the original article can be found under doi:10.1007/s11109-014-9267-3.

\section{R. E. Carlin}

Political Science Department, Georgia State University, Atlanta, GA, USA

e-mail: rcarlin@gsu.edu

G. J. Love ( $ه)$

Political Science Department, University of Mississippi, University, MS, USA

e-mail: gjlove@olemiss.edu

C. Martínez-Gallardo

Political Science Department, University of North Carolina at Chapel Hill, Chapel Hill, NC, USA

e-mail: cmg@email.unc.edu 


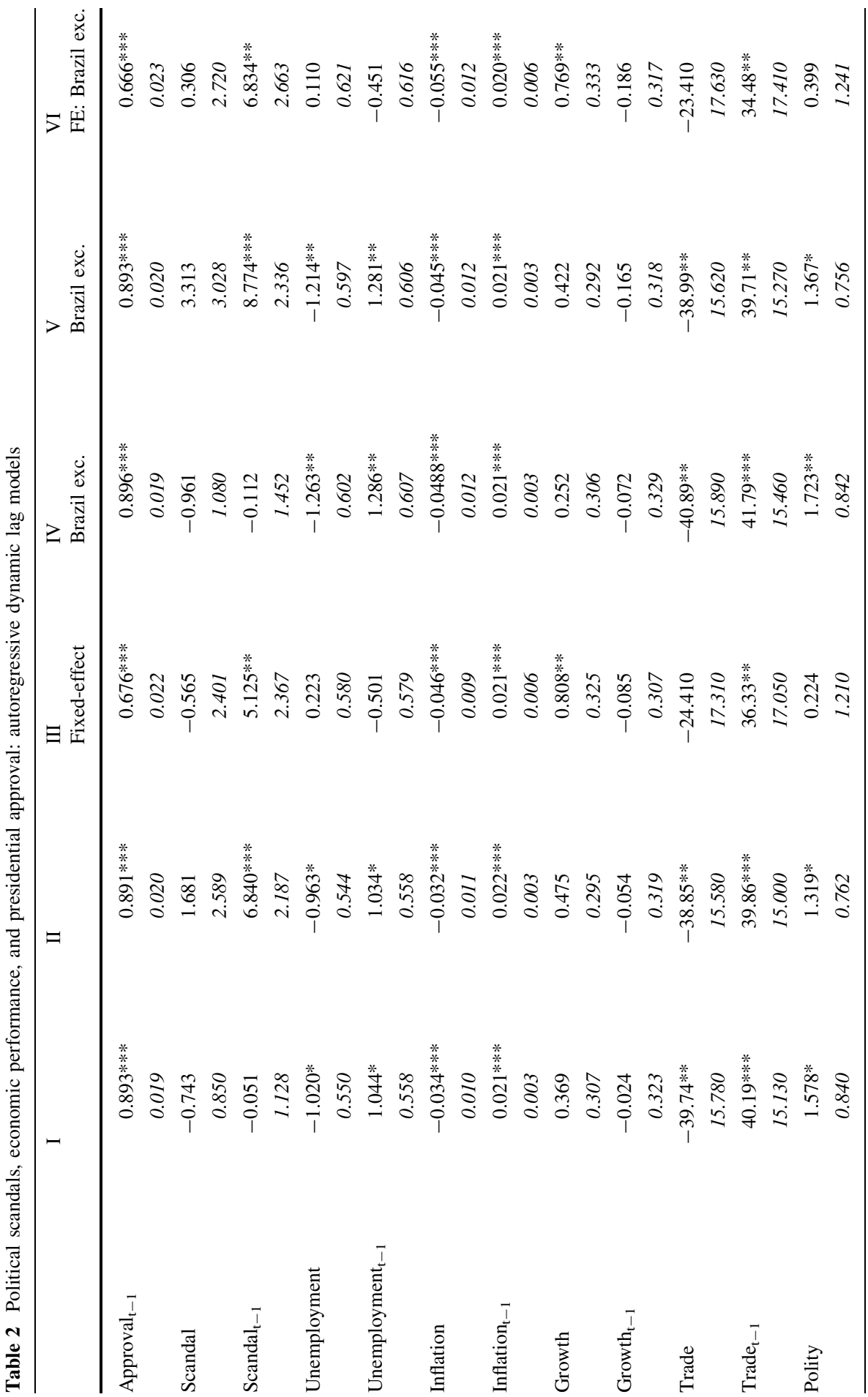




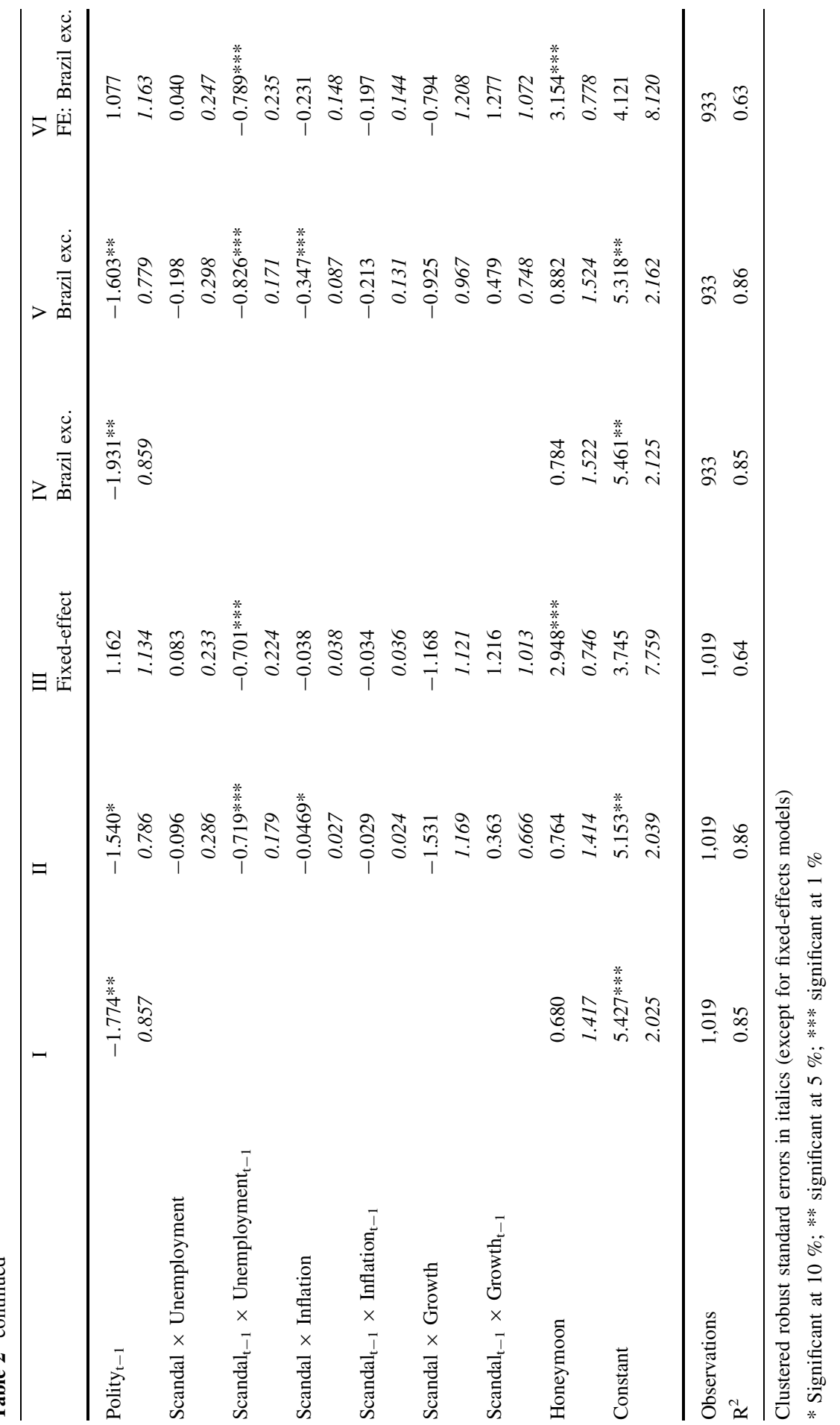

